\title{
Effects of protection from fishing on the lengths of targeted and non-targeted fish species at the Houtman Abrolhos Islands, Western Australia
}

\author{
Dianne L. Watson ${ }^{1, *}$, Marti J. Anderson ${ }^{2}$, Gary A. Kendrick ${ }^{3}$, Kim Nardi ${ }^{4}$, \\ Euan S. Harvey ${ }^{3}$ \\ ${ }^{1}$ Centre for Marine Futures / School of Plant Biology, The University of Western Australia, 35 Stirling Highway, \\ Crawley, Western Australia 6009, Australia
}

${ }^{2}$ Institute of Information and Mathematical Sciences, Massey University, Auckland, Albany Private Bag 102 904, New Zealand ${ }^{3}$ School of Plant Biology, The University of Western Australia, 35 Stirling Highway, Crawley, Western Australia 6009, Australia ${ }^{4}$ Department of Fisheries, Western Australia, PO Box 1171, Geraldton, Western Australia 6531, Australia

\begin{abstract}
The effects of fishing and protection on the length of targeted and non-targeted warmtemperate and tropical reef fishes were studied using baited remote underwater stereo-video cameras at the Houtman Abrolhos Islands, Western Australia. Video images were obtained from inside a marine protected area (MPA) and from 3 replicate fished locations within each of 3 island groups. The effects of protection on the lengths of 6 targeted and 4 non-targeted fish species were examined. Five of the 6 targeted fish species were larger inside MPAs than in areas open to fishing (Choerodon rubescens, Lethrinus miniatus, Lethrinus nebulosus, Pagrus auratus and Plectropomus leopardus). Targeted species were, on average, $48 \mathrm{~mm}(10 \%)$ larger inside MPAs than in areas open to fishing. The vast majority of the individuals of C. rubescens, $P$. auratus and $P$. leopardus recorded were smaller than their minimum legal size for first capture. For non-targeted species, only 1 of the 4 , Coris auricularis, showed an effect of protection, with the mean length of individuals reduced by $85 \mathrm{~mm}(33 \%)$ inside MPAs relative to areas open to fishing. This study demonstrated clear effects of protection from fishing on the size structure of populations of common warm-temperate and tropical reef fishes.
\end{abstract}

KEY WORDS: Marine protected areas · Fish length $\cdot$ Houtman Abrolhos Islands · Baited remote stereo-video $\cdot$ Coral reefs

\section{INTRODUCTION}

Exploitation of fisheries may be recognised by a measured reduction in the biomass of targeted large species, which are often top predators in an ecosystem (Jennings \& Polunin 1997, DeMartini et al. 2008). Given the life-history characteristics of many targeted fish species occupying relatively high trophic levels (that is, being long-lived and slow-growing, e.g. Lethrinidae, Serranidae), selective fishing of such species makes them particularly vulnerable to overfishing (Pauly et al. 2002). Furthermore, the removal of large high-trophic-level fish species from an ecosystem is likely to have significant indirect effects on their prey and competitors, and ultimately on the ecosystem's assemblage structure and dynamics as a whole (DeMartini et al. 2008). The establishment of areas where no fishing is permitted is a spatial management strategy to protect marine ecosystems against direct and indirect effects of fishing.

The establishment of marine protected areas (MPAs) can result in an increase in the fish abundance, length and biomass of targeted fish species within their boundaries (e.g. Harborne et al. 2008). Most commonly, this information has been collected by SCUBA divers conducting an underwater visual census (UVC) 
(e.g. Kulbicki et al. 2007). However, biases and limitations of UVC have spurred the development and use of alternative sampling techniques, including remote video. Stereo-video systems can obtain much more accurate and precise measures of the lengths of individual fish than either estimation by divers or single video camera systems (Harvey \& Shortis 1996, Harvey et al. 2002). Remote stereo-video systems have the added advantage of providing information on the effects of fishing on the length of fishes at depths inaccessible to SCUBA divers (Australian Occupational Health and Safety guidelines severely restrict the time that researchers can spend at depths greater than $20 \mathrm{~m}$ in Australia). We used baited remote underwater stereo-video systems (stereo BRUVs) to assess the size structure of fish assemblages in areas open and closed to fishing to depths greater than $25 \mathrm{~m}$ at the Houtman Abrolhos Islands, Western Australia.

MPAs at the Houtman Abrolhos Islands were established in 1994 to protect valuable and vulnerable reef fish from overfishing. These areas, originally termed Reef Observation Areas, are not strictly notake, as rock lobster Panulirus cygnus fishing (only) is permitted within their boundaries. Outside the MPAs a commercial and recreational fishery for demersal reef fish exists that is currently managed by minimum legal sizes for capture and recreational bag limits (Nardi et al. 2004). Approximately 23 charter vessels were recorded to operate at the Abrolhos Islands in 2006 (Sumner 2008). Other fishing sectors operating at the Houtman Abrolhos include: recreational fishers, commercial wetliners (reel and line demersal fishers) and commercial rock lobster fishers.

Nardi et al. (2004) assessed the abundance of coral trout Plectropomus leopardus and baldchin groper Choerodon rubescens before MPA establishment and for the following $8 \mathrm{yr}$ at the Houtman Abrolhos Islands. No significant differences in abundance were detected for either species before MPA establishment, but significant increases in the average abundance were observed for $P$. leopardus $4 \mathrm{yr}$ after MPAs were established (Nardi et al. 2004). More recently, Watson et al. (2007) found greater relative abundances of several heavily targeted fish species inside MPAs at the islands compared with areas open to fishing. For non-targeted species the effects of protection varied, with some species being more abundant inside MPAs, while others were more abundant in areas open to fishing (Watson et al. 2007). While Nardi et al. (2004) and Watson et al. (2007) provided clear evi- dence that fishing depletes the abundance of targeted species at the Houtman Abrolhos, accurate estimates of the potential effects of fishing (or protection from fishing) on fish lengths across a broad range of species have not been obtained. We predicted that targeted species would be larger, on average, inside MPAs compared with unprotected areas. For non-targeted species, we predicted no significant differences in mean lengths of fish between MPA and fished locations.

\section{MATERIALS AND METHODS}

Study site. The Houtman Abrolhos Islands are an A-class Reserve located $60 \mathrm{~km}$ offshore from the midwest coast of Western Australia on the edge of the continental shelf between $28^{\circ} 15^{\prime} \mathrm{S}$ and $29^{\circ} \mathrm{S}$ (Fig. 1). The 122 islands that make up the Houtman Abrolhos are clustered into 4 main groups that run parallel to the mainland in a north-south orientation that spans $100 \mathrm{~km}$. From north to south these groups are the

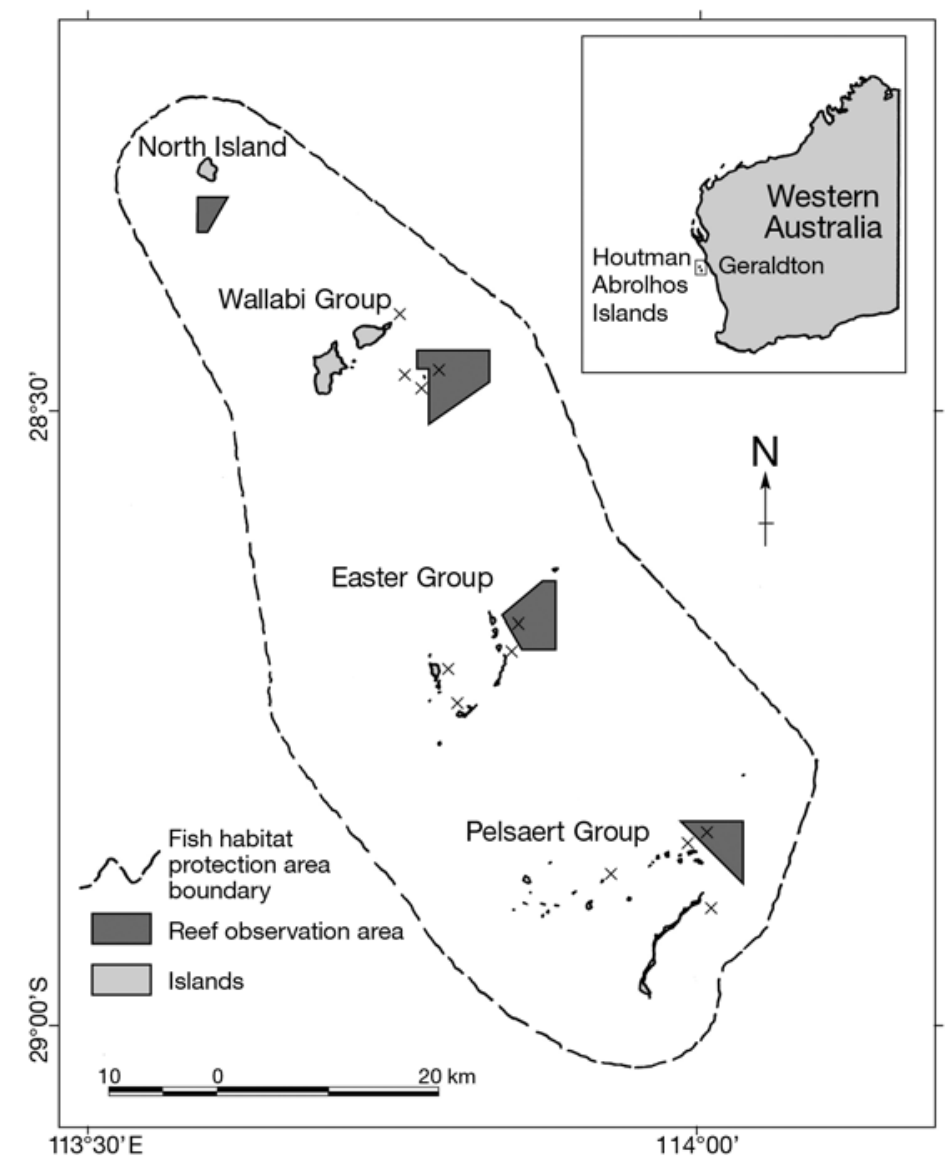

Fig. 1. Houtman Abrolhos Islands, Western Australia. The location of each island group and marine protected area (also known as Reef Observation Area) is shown in addition to the 3 areas open to fishing surveyed within each island group. $\times$ denotes sites surveyed. Map courtesy of the Department of Fisheries, Western Australia 
North Island, Wallabi group, Easter group and the Pelsaert group (Fig. 1). The islands lie in the path of the warm southward-flowing Leeuwin current that allows the Houtman Abrolhos to possess the most southern true coral reefs of the Indian Ocean. The islands are unique, having tropical and temperate climates that overlap and containing an interesting mix of tropical fish and corals with temperate fish and kelp forests.

Two surveys were carried out at the Wallabi, Easter and Pelsaert Island groups of the Houtman Abrolhos from 5 to 10 November 2004 and from 1 to 6 May 2005. The North Island was not surveyed during this study due to time constraints. At each island group, stereo BRUV surveys were conducted within the MPA and at 3 nearby unprotected locations, where fishing is known to occur (Fig. 1). Three replicate fished or 'reference' locations were surveyed at each island group due to high expected natural variability among locations and the absence of any comparable 'before' data prior to reserve establishment (see Glasby 1997). The Wallabi group MPA is the largest of the $3\left(27.44 \mathrm{~km}^{2}\right)$, followed by the Easter group MPA $\left(22.29 \mathrm{~km}^{2}\right)$ and the Pelsaert group MPA (13.72 $\left.\mathrm{km}^{2}\right)$. Shallow (8 to $12 \mathrm{~m}$ ) and deep (22 to $26 \mathrm{~m}$ ) reef slopes were surveyed at each of the MPA and nearby fished locations. These MPAs were established in 1994 down the eastern margin of the Houtman Abrolhos in areas of high coral cover. Using direct observation, echo-sounder readings and the skipper's knowledge of the area, care was taken to standardise surveys such that fished locations and MPAs possessed similar coral habitats. The percentage cover of different habitat types was also estimated from freeze-framed video images for every site. Formal analyses indicated no significant differences in habitat structure between MPA and fished locations (see Watson et al. 2007 for details). Five replicate sites were sampled within each combination of 3 island groups $\times 4$ locations ( 1 MPA and 3 fished within each island group) $\times 2$ depths. This resulted in a total of 120 sites surveyed (90 fished sites and 30 sites inside the MPAs) using the stereo BRUVs.

Sampling technique. Stereo BRUVs used in the present study were the same as those used by Harvey et al. (2002) and Watson et al. (2005, 2007) and are termed 'remote' because the systems are freestanding on the seafloor without the need for an operator. Two HC 15E video cameras (Sony) are mounted $0.7 \mathrm{~m}$ apart on a base bar inwardly converged at $8^{\circ}$ to gain an optimized field of view with visibility of at least $10 \mathrm{~m}$ distance (Harvey \& Shortis 1996). Detailed information on the design, calibration, use and analysis of video footage obtained from remote stereo-video systems can be found elsewhere (i.e. Harvey \& Shortis 1996, Harvey et al. 2001). Importantly, the use of stereovideo allows accurate estimates of distance (Harvey et al. 2004). The standardized field of view sampled by the stereo BRUV system in this study was from 0 to $8 \mathrm{~m}$ inclusive from the cameras.

Stereo BRUVs were deployed by boat and filmed on the sea floor for a period of $1 \mathrm{~h}$ (maximum video tape length). Systems were deployed no earlier than 8:00 h or later than 16:00 h. Bait consisted of $800 \mathrm{~g}$ of pilchards Sardinops sagax in a closed plastic-coated wire basket that was suspended approximately $1.2 \mathrm{~m}$ in front of the 2 cameras. The pilchards were crushed to promote dispersal of the fish oil. Adjacent sites were separated by 250 to $400 \mathrm{~m}$ to reduce the likelihood of fish moving between sites within the sampling period. This distance is based on the estimated swimming speeds of common reef fish species and the distance they may travel over a sampling period (Cappo et al. 2001). Upon retrieval, video footage was examined to ensure that the stereo BRUV system landed upright to film horizontally along the reef and that the field of view was not obstructed by habitat features. Where systems landed on an angle or were obstructed, they were re-deployed on subsequent days or in another nearby location (250 to $400 \mathrm{~m}$ away).

The use of bait often raises concerns about biases that may affect results obtained. First, we would expect stereo BRUVs (like baited single-camera BRUVs) to be more effective at sampling larger predatory piscivores than smaller and herbivorous fishes. Second, the bait plume dynamics will vary with depth and localized conditions, such as small-scale habitat, seafloor topography and currents. Third, the behavioral response of fish to bait is expected to vary among fish of different species, different sizes and olfactory perception. We surveyed sites of similar habitat, depth and exposure in MPA and fished locations to minimize any variation that might be introduced by such factors. Thus, although stereo BRUVs, even when used consistently, can only provide relative, as opposed to absolute, measures of either densities or sizes of fish, we assumed that any methodological biases or localized effects were not correlated in any systematic or directional way with the areas being contrasted (i.e. inside versus outside MPAs).

Length measurements. To avoid making repeated measurements of the same individuals, measures of fork length (FL, snout to fork) were made at the time at which the maximum number of fish belonging to each species was visible in the field of view of the cameras (MaxN = relative abundance) (Priede et al. 1994, Cappo et al. 2004). This MaxN 'time' is not instantaneous; rather it corresponds to the length of time all individuals remain in the field of view of the stereo BRUVs. MaxN is a conservative measure of relative abundance (Willis et al. 2000) as the measure only permits counts of individuals that are observed within the 
field of view at the same time. On occasion, different individuals could be identified by dramatic differences in size, despite not being viewed within the MaxN time frame. In such cases, these individuals were also measured. FL was measured instead of total length (TL) as it was considered to be a more reliable measure; TL may be affected by the angle of the tail seen in an image or by tail damage. Lengths reported here (FL) will therefore be slightly smaller than $\mathrm{TL}$, which is used in regulating minimum legal size for first capture. Therefore, comparisons between the lengths of fish measured here and their minimum legal size will not be exact, but close, particularly for species with emarginate tails (e.g. Choerodon rubescens, Plectropomus leopardus). To avoid observer bias, a single researcher conducted all fish identifications, relative abundance counts and length measures.

From MaxN data, 10 species were chosen for length measurement because they are targeted by commercial and recreational fishers, or are common and abundant at the islands (Table 1). These 10 selected species represented $43 \%$ (2004) and $46 \%$ (2005) of the total number of individuals observed on stereo BRUVfootage, but only $9 \%$ (2004 and 2005) of the total number of species observed (see Watson et al. 2007). Although several non-targeted fish species were viewed more commonly on video footage than were Kyphosus sydneyanus (Table 1), these species often not measurable from video images due to their body shape and/or cryptic nature (e.g. Gymnothorax woodwardi, G. prasinus, Labracinus lineatus). The endemic and vulnerable species, the West Australian dhufish Glaucosoma hebraicum was excluded from the analyses due to very low numbers (8 individuals).

FL was measured from digitally captured images in the computer program PhotoMeasure (SeaGIS 2008). To ensure good measurement accuracy and precision, as well as a standardised sampling unit, measures of fish length were limited to within a maximum distance of $8 \mathrm{~m}$ from the cameras. The software calculates both distance from the cameras and length at the same time. During the study period, visibility was excellent and consistently $>8 \mathrm{~m}$. Time for length analysis varied according to the numbers of species and individuals present at a site. Typically, a full 60 min deployment at the Houtman Abrolhos would take up to $2 \mathrm{~h}$ to analyse in the laboratory, i.e. to count and measure all individuals identified to species level.

Data analysis. Sampling was designed to provide robust estimates of marine protected area effects on sizes of fish across multiple sites from 3 island groups at 2 depths and over 2 years of sampling. Of central interest was to estimate the effect of protection on the average lengths of several targeted and non-targeted fish species. A mixed model analysis of the length data was done with the following factors: Protection $(\mathrm{P}, \mathrm{a}$ fixed factor with 2 levels, fished and MPA), Targeted $(\mathrm{T}$, a fixed factor with 2 levels, targeted and nontargeted) and Species(T) (i.e. Species as a random factor nested in $\mathrm{T}$, with 4 non-targeted and 6 targeted species, Table 1). Species were treated as a random factor because the effects of reserves were expected to vary among species (a component of variation we wished to measure directly) and individual species are either targeted or non-targeted (they cannot be both), requiring this factor to be nested within the factor $\mathrm{T}$ for purposes of analysis. Our expectation was that the protection afforded by MPAs would affect the average lengths of fish differently, depending on whether they were targeted or non-targeted (i.e. to yield a significant $\mathrm{P} \times \mathrm{T}$ interaction). More specifically, we expected large positive effects of protection for targeted species, but little or no effects for non-targeted species.

Table 1. The family, genus, species and common name for each of 10 fish species selected for measurement. Non-targeted species (NT) and those species commonly targeted by fishers (T) are indicated, in addition to the percentage of sites at which each was recorded

\begin{tabular}{|c|c|c|c|c|c|}
\hline \multirow[t]{2}{*}{ Family } & \multirow[t]{2}{*}{ Species } & \multirow[t]{2}{*}{ Common name } & \multirow[t]{2}{*}{$\begin{array}{c}\text { Targeted or } \\
\text { non-targeted }\end{array}$} & \multicolumn{2}{|c|}{$\begin{array}{l}\text { Mean \% sites } \\
(2004 \text { \& 2005) }\end{array}$} \\
\hline & & & & MPAs & Fished \\
\hline Lethrinidae & Lethrinus nebulosus (Forskål, 1775) & Spangled emperor & $\mathrm{T}$ & 39 & 18 \\
\hline Sparidae & Pagrus auratus (Schneider, 1801) & Pink snapper & $\mathrm{T}$ & 31 & 42 \\
\hline Labridae & Choerodon rubescens (Günther, 1862) & Baldchin groper & $\mathrm{T}$ & 57 & 73 \\
\hline Serranidae & Plectropomus leopardus (Lacepède, 1802) & Coral trout & $\mathrm{T}$ & 61 & 61 \\
\hline Carangidae & Pseudocaranx dinjerra & Skipjack trevally & $\mathrm{T}$ & 24 & 32 \\
\hline Lethrinidae & Lethrinus miniatus (Schneider, 1801) & Redthroat emperor & $\mathrm{T}$ & 44 & 33 \\
\hline Kyphosidae & Kyphosus sydneyanus (Günther, 1886) & Common buffalo bream & NT & 21 & 10 \\
\hline Scaridae & Scarus schlegeli (Bleeker, 1861) & Schlegel's parrotfish & NT & 54 & 62 \\
\hline Labridae & Coris auricularis (Valenciennes, 1839) & $\begin{array}{l}\text { Western king wrasse } \\
\text { ( } 0^{1} \text { and o separate) }\end{array}$ & NT & 18 & 51 \\
\hline Labridae & Thalassoma lunare (Linnaeus, 1758) & Moon wrasse & NT & 12 & 33 \\
\hline
\end{tabular}


Lengths of fish measured from a single stereo BRUV unit at a given point in time and space are not independent of one another. The true replicate sampling units were the individual stereo BRUV deployments, and not the individual fish. We therefore considered Deployment (D) as a random factor (nested within P) in the analysis. The number of fish of any particular species measured within a single deployment varied considerably across the study design, yielding an inherently unbalanced design (see Table 2 for details).

The 4-factor mixed-effects unbalanced linear model was fitted to the length data using restricted maximum likelihood (REML, e.g. see Pinheiro \& Bates 2004). Variance components for all random effects were estimated using best linear unbiased estimators (BLUE). Tests of fixed effects were done using Type III sums of squares and approximate F-tests, with corrections to Satterthwaite's (1941) approximations to the degrees of freedom as provided by Kenward \& Roger (1997) and bias-correction for small samples as provided by Kackar \& Harville (1984). Significant interaction terms for fixed effects were examined further using Tukey's honestly significant difference (HSD) multiple comparisons. Models were fitted using JMP v. 7 software and double-checked using the SAS 'proc mixed' routine. Individual estimates of the reserve effect for each species (and associated confidence limits) were obtained using the 'ImList' function in the R computer program (R Development Core Team 2008), which was also used to produce all graphics (e.g. Murrell 2006).

\section{RESULTS}

Distributions of fish lengths were strongly unimodal and fairly symmetric (Fig. 2). Diagnostic plots indicated that the assumptions underlying the use of the linear model were quite reasonable for the length data, par-

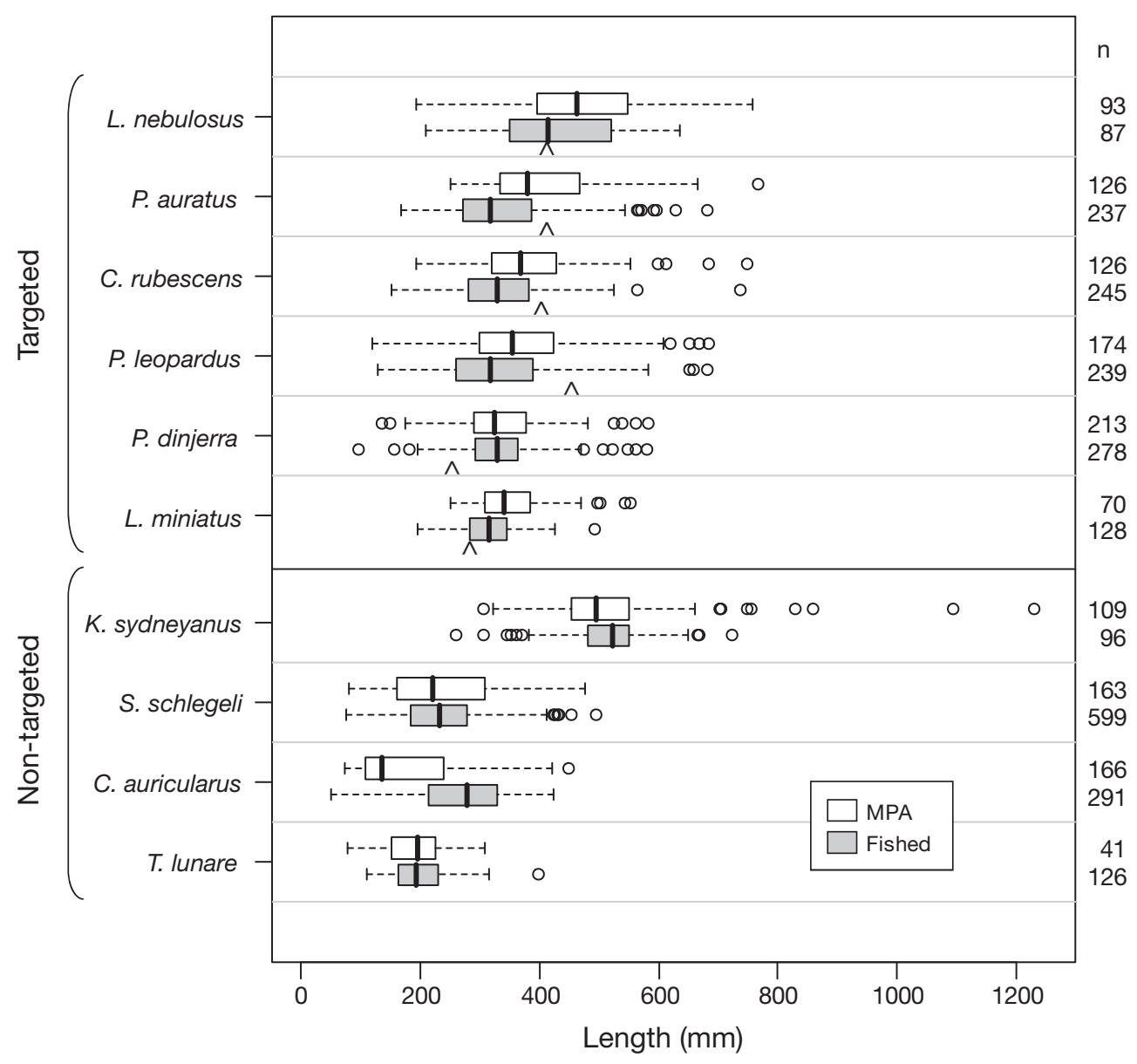

Fig. 2. Boxplots of the lengths of fishes observed in the MPA and fished sites for 4 non-targeted and 6 targeted species. The symbol $\wedge^{\wedge}$ is used to identify the minimum legal size for each of the targeted species. Within each category (targeted and non-targeted), fish species are ordered top to bottom from largest to smallest average length (observed in this study). The sample sizes for the number of individuals are also given to the right of each box (n). Note that greater total numbers of individuals were measured from fished locations, due to a greater sampling effort in these areas (i.e. there were 3 fished locations for each single MPA) 
ticularly with such large sample sizes. Median lengths of non-targeted fish were generally smaller than those of targeted fish, except for the silver drummer Kyphosus sydneyanus, which were relatively large, including 2 large fish measured inside MPAs (>1 m FL). The median length of fish inside MPAs was larger than that at fished sites for 5 out of the 6 targeted fish species measured, with the exception being skipjack trevally Pseudocaranx dinjerra (Fig. 2). In contrast, 3 out of the 4 non-targeted species had smaller median lengths inside MPAs, a pattern that was especially marked for the western king wrasse Coris auricularis (Fig. 2). Over $50 \%$ of the fish measured from populations of pink snapper Pagrus auratus, baldchin groper and coral trout were smaller than current minimum legal sizes. However, the opposite was true for populations of redthroat emperor Lethrinus miniatus, spangled emperor Lethrinus nebulosus and skipjack trevally.

All of the random effects were significantly different from zero in the linear mixed model (Table 2). The relative sizes of the variance components indicated that variation among species was (not surprisingly) the greatest of the components measured. In addition, the effects of protection varied significantly among species, i.e. the confidence interval $(\mathrm{CI})$ for the $\mathrm{P} \times \mathrm{Spe}$ cies(T) component did not include zero, indicating that individual estimates of this effect should be obtained separately for each species. Over and above this species-specific variability, however, the $\mathrm{P} \times \mathrm{T}$ interaction was also clear $(p=0.01$, Table 2$)$. More specifically, targeted fish measured inside the marine reserves were significantly larger than those measured in fished areas (Tukey's HSD, $\mathrm{p}<0.05$ ). Targeted fish were estimated to be $48 \pm 11.5 \mathrm{~mm}$ (mean $\pm \mathrm{SE}$ ) or $10 \%$

Table 2. Tests of fixed effects and estimates of variance components for random effects from the full unbalanced mixed model of fish lengths using restricted maximum likelihood (REML). Parentheses indicate a nested structure, e.g. Deployment $(\mathrm{P})=$ Deployment, nested in Protection

\begin{tabular}{|lrrrr|}
\hline Fixed effects & $\begin{array}{c}\text { Numerator } \\
\mathrm{df}\end{array}$ & $\begin{array}{r}\text { Denominator } \\
\mathrm{df}\end{array}$ & $F$ ratio & $\mathrm{p}$ \\
\hline Protection (P) & 1 & 25.63 & 6.382 & 0.0181 \\
Targeted (T) & 1 & 7.85 & 1.161 & 0.3133 \\
$\mathrm{P} \times \mathrm{T}$ & 1 & 12.43 & 9.204 & 0.0100 \\
\hline Random effects & Variance & $\mathrm{SE}$ & $95 \% \mathrm{CI}$ & $\%$ of total \\
& component & & & \\
\hline Deployment(P) & 425.63 & 219.80 & $(190,1654)$ & 2.68 \\
Species(T) & 8298.86 & 4279.64 & $(3713,32160)$ & 52.24 \\
P $\times$ Species(T) & 127.98 & 98.81 & $(43,1428)$ & 0.81 \\
T $\times$ Deployment(P) & 261.72 & 153.93 & $(107,1322)$ & 1.65 \\
Deployment(P) $\times$ Species(T) & 770.71 & 142.66 & $(553,1149)$ & 4.85 \\
Residual & 6002.16 & 145.87 & $(5726,6299)$ & 37.78 \\
Total & 15887.06 & & & 100.00 \\
\hline
\end{tabular}

longer, on average, inside protected areas, whereas no significant effect of protection was detected overall for the non-targeted species.

Individual estimates of protection effects showed that 5 of the 6 targeted species (all except Pseudocaranx dinjerra) were significantly longer (between 35 and $69 \mathrm{~mm}$, on average) inside MPAs, compared with fished areas (Fig. 3). In contrast, there was no significant effect of protection detected for 3 out of the 4 non-targeted species. Coris auricularis was the only species to show a significantly shorter average length inside MPAs, compared with fished areas, with the MPA effect estimated to be $-85 \mathrm{~mm}(-33 \%$; Fig. 3).

\section{DISCUSSION}

A reduced length of heavily targeted species Lethrinus miniatus, L. nebulosus, Plectropomus leopardus, Choerodon rubescens and Pagrus auratus in areas open to fishing demonstrates a clear effect of fishing at the Houtman Abrolhos Islands. This finding supports an ever-growing number of studies that show fishing strongly affects the size of targeted species in a population (e.g. Bianchi et al. 2000, Tetreault \& Ambrose 2007, DeMartini et al. 2008). Here we extend on this body of knowledge with a highly accurate measurement technique (stereo BRUVs) to reduce equivocal results obtained from UVC methods, observer bias and destructive trapping and trawling methods. A reduction in targeted species' sizes in fished areas at the Houtman Abrolhos is probably due to the combined effects of fishers targeting larger individuals (sizeselective fishing or 'age truncation', Berkeley et al. 2004) and an increased catchability of larger individuals (more likely to take a bait). Size selective fishing can have important effects on fish assemblage structure and function, potentially affecting the productivity and resilience of some stocks (Olsen et al. 2004, Baskett et al. 2005). For protogynous hermaphrodite species (e.g. C. rubescens, P. leopardus, L. miniatus, L. nebulosus) the removal of larger individuals, presumably males, can potentially cause sperm limitation in a population (Hamilton et al. 2007). Differences in the size structure of fish assemblages between MPAs and fished locations at the Houtman Abrolhos Islands, combined with changes in their relative abundances (Watson et al. 2007), indicates localised depletion of 


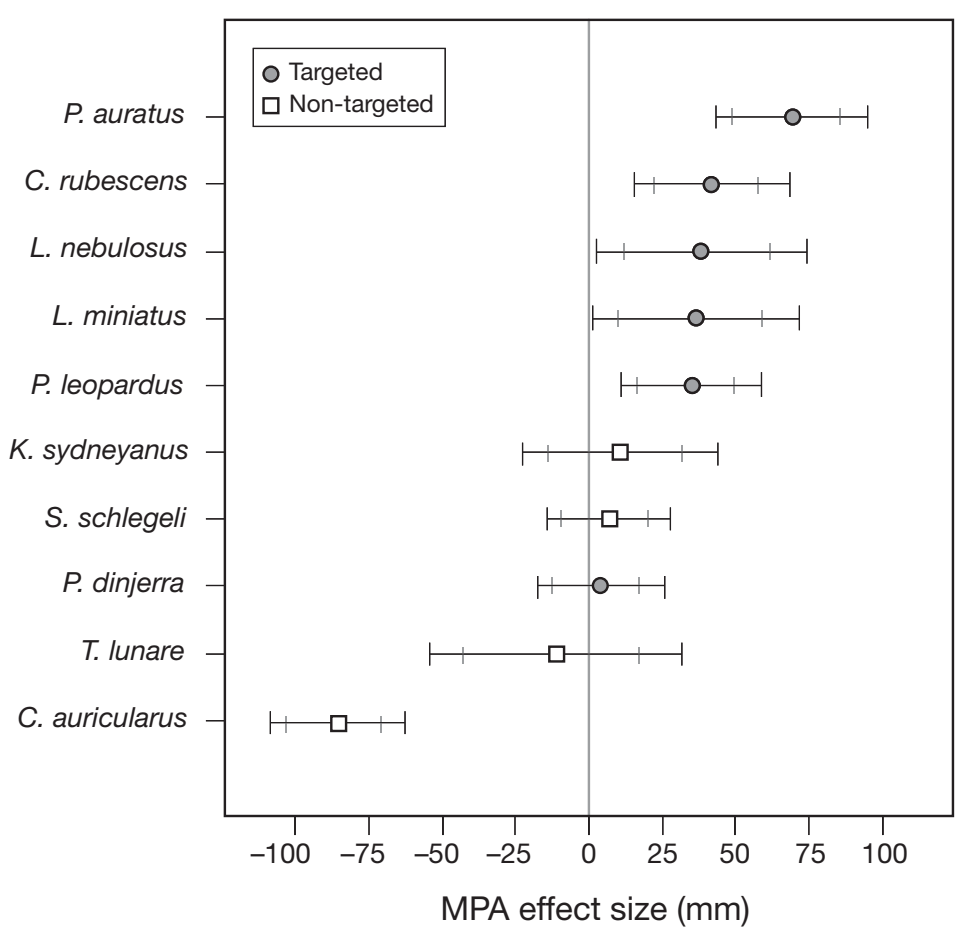

Fig. 3. Estimated average difference in length between fish measured at protected sites compared with unprotected sites (i.e. the MPA effect size). The confidence intervals (CIs) shown are given at the Bonferroni adjusted level of $99.5 \%$ (i.e. for 10 tests, the adjusted $\alpha$-level $=$ $0.05 / 10=0.005$ ). Grey vertical bars indicate the uncorrected $95 \%$ CI on the effect size for each species. The 10 species are listed from top to bottom in order from largest to smallest effect size

targeted baldchin groper, coral trout, pink snapper and the emperor species.

Very few individuals of Pagrus auratus, Choerodon rubescens and Plectropomus leopardus, either inside or outside MPAs, were larger than the minimum legal size for first capture. While this is likely to be a direct result of size-selective fishing, the presence of the same pattern for fish within MPA boundaries suggests that this may be the natural size structure for these populations. That is, perhaps only a small proportion of these populations naturally exist in size categories larger than their assigned minimum legal size. Alternatively, there may be size-selective fishing occurring in fished areas and density-dependent growth occurring within MPAs (see Gårdmark et al. 2006).

Minimum legal sizes for first capture must, most importantly, permit individuals to reach sexual maturity to enable sustainability of the stock. While the majority of Choerodon rubescens and Pagrus auratus are smaller than their minimum legal size, most are larger than size at sexual maturity (Paul 1976, Nardi et al. 2006). However, the majority of individuals of Plectropomus leopardus observed in the present study were not just smaller than minimum legal size, they were also smaller than size at maturity (320 to $360 \mathrm{~mm}$ TL, Ferreira 1995). This has important implications for the sex ratios of this species as it is a protogynous hermaphrodite. Thus, males in the population are especially subject to fishing pressure, potentially making the species vulnerable to sperm limitation (e.g. Hamilton et al. 2007). Size-selective fishing of $P$. leopardus could also result in sex change occurring earlier in the life cycle (Hamilton et al. 2007, Molloy et al. 2008, Sattar et al. 2008). Furthermore, populations of $P$. leopardus at the Houtman Abrolhos are genetically isolated (van Herwerden et al. 2006). This isolation would predictably exacerbate effects of overfishing of this species by limiting the exchange and supply of new recruits.

An increased size of targeted species within MPA boundaries is extremely important as this increased size correlates to higher biomass and fecundity. A $10 \%$ increase in length inside MPAs can equate to 25 to $30 \%$ higher biomass for fishes in these areas. If we were to consider only legal-sized fishes, then the increase in length inside MPAs would be even higher (e.g. Tetreault \& Ambrose 2007). Populations within MPAs certainly have older, larger and more fecund fish, capable of producing more larvae with greater survival potential than their smaller counterparts (Berkeley et al. 2004). Through dispersion of these larvae, MPA populations have the potential to replenish stocks in areas open to fishing (Francini-Filho \& Moura 2008). Whether this occurs may depend on how MPA sizes and their spatial distribution interact with oceanographic conditions, larval dispersal and larval life history characteristics (e.g. time in the plankton). To determine whether the increased sizes of individuals within MPA boundaries is actually benefiting adjacent fisheries at the Houtman Abrolhos Islands (i.e. whether there is cross-subsidy), rigorous stock assessments of abundance and productivity, including simulations under varying degrees of fishing pressure, need to be done.

In contrast to targeted fishes, the majority of nontargeted fish species measured here did not exhibit differences in length between MPA and fished locations (see also Tetreault \& Ambrose 2007). The single non-targeted species that did show an effect, Coris auricularis, was estimated to be $33 \%$ larger in fished areas than in MPAs. It is highly likely that this is an indirect effect. C. auricularis may reach larger sizes in areas open to fishing due to reduced abundances and sizes of one of its predators, Plectropomus leopardus 
(St John 1999, Watson et al. 2007). It is possible that the removal of large individuals by fishing at the Houtman Abrolhos Islands promotes increases in the biomass of several common prey species.

Here, the use of remote stereo video technology permitted the lengths of more than 3600 individuals to be measured accurately (to within a few millimetres) and non-destructively, from depths below the legal limits for research divers. Measurement accuracy is important, as it facilitates detection of differences in fish size between MPA and fished locations, even where differences may be small. This is not often possible for diver surveys where estimates can be variable between observers and estimates are time-consuming to obtain in the field. Stereo BRUVs do, however, have limitations. The measured effects of protection on lengths of fishes could have been influenced by inter- or intraspecific behavioural interactions. For example, larger individuals may have deterred smaller fish from approaching the bait. While no obvious systematic differences in behaviour were noted between assemblages in fished versus MPA locations, the potential effects of protection on behavioural interactions is a subject warranting further study. By standardizing across habitats and depths we have assumed only that whatever biases are inherent to the method have remained consistent across the study design, thus yielding rigorous and accurate measures of effect sizes.

MPA zoning has resulted in changes in the abundances (Watson et al. 2007) and size distributions (the present study) of several targeted high-trophic-level predatory fish in the Houtmans Abrolhos Islands, Western Australia. Fisheries management practices are clearly enhancing the survival of targeted fished species within MPA boundaries, but not necessarily that of non-targeted species. Further research is needed to assess cause-effect pathways, quantify potential cross-subsidies, and determine whether MPAs genuinely work on appropriate spatial and temporal scales to contribute to populations and ensure long-term sustainability of fisheries.

Acknowledgements. This study was conducted with logistical assistance from the Department of Fisheries Western Australia (DoF). Financial assistance was received from The University of Western Australia (UWA) and from the Western Australia and Australian Governments Natural Heritage Trust initiative (NHT) through the Northern Agricultural Catchment Council (NACC). We thank Sony Australia and R. Scott in the UWA workshop for construction of the stereovideo systems. We greatly appreciate the help given by Dr. B. Hutchins in identifying numerous fish species and for comments on the draft manuscript. We are extremely grateful to Dr. J. Meeuwig, Dr. R. Cole and M. Cappo for their review and improvements to drafts of the manuscript.

\section{LITERATURE CITED}

Baskett ML, Levin SA, Gaines SD, Dushoff J (2005) Marine reserve design and the evolution of size at maturation in harvested fish. Ecol Appl 15:882-901

Berkeley SA, Hixon MA, Larson RJ, Love MS (2004) Fisheries Sustainability via protection of age structure and spatial distribution of fish populations. Fisheries 29(8):23-31

Bianchi G, Gislason H, Graham K, Hill L and others (2000) Impact of fishing on size composition and diversity of demersal fish communities. J Mar Sci 57:558-571

Cappo M, Speare P, Wassenberg TJ, Harvey E, Rees M, Heyward A, Pitcher R (2001) Use of baited remote underwater video stations (BRUVS) to survey demersal fish-How deep and meaningful? In: Harvey ES, Cappo M (eds) Direct sensing of the size frequency and abundance of target and non-target fauna in Australian Fisheries. 4-7 September 2000, Rottnest Island, Western Australia. Fisheries Research and Development Corporation, Deakin ACT, p 63-71

Cappo M, Speare P, De'ath G (2004) Comparison of baited remote underwater video stations (BRUVS) and prawn trawls for assessments of fish biodiversity in inter-reefal areas of the Great Barrier Reef Marine Park. J Exp Mar Biol Ecol 302:123-152

DeMartini E, Friedlander AM, Sandin SA, Sala E (2008) Differences in fish-assemblage structure between fished and unfished atolls in the northern Line Islands, central Pacific. Mar Ecol Prog Ser 365:199-215

Ferreira BP (1995) Reproduction of the common coral trout Plectropomus leopardus (Serranidae, Epinephelinae) from the Central and Northern Great Barrier Reef, Australia. Bull Mar Sci 56:653-669

Francini-Filho RB, Moura RL (2008) Evidence for spillover of reef fishes from a no-take marine reserve: an evaluation using the before-after control-impact (BACI) approach. Fish Res 93:346-356

Gårdmark A, Jonzén N, Mangel M (2006) Density-dependent body growth reduces the potential of marine reserves to enhance yields. J Appl Ecol 43:61-69

Glasby TM (1997) Analysing data from post-impact studies using asymmetrical analyses of variance: a case study of epibiota on marinas. Aust J Ecol 22:448-459

Hamilton SL, Caselle JE, Standish JD, Schroeder DM, Love MS, Rosales-Casian JA, Sosa-Nishizaki O (2007) Sizeselective harvesting alters life histories of a temperate sexchanging fish. Ecol Appl 17:2268-2280

> Harborne AR, Mumby PJ, Kappel CV, Dahlgren CP and others (2008) Reserve effects and natural variation in coral reef communities. J Appl Ecol 45:1010-1018

Harvey ES, Shortis MR (1996) A system for stereo-video measurement of subtidal organisms. Mar Technol Soc J 29: $10-22$

Harvey E, Fletcher D, Shortis M (2001) Improving the statistical power of length estimates of reef fish: a comparison of estimates determined visually by divers with estimates produced by a stereo-video system. Fish Bull 99:72-80

Harvey E, Fletcher D, Shortis M (2002) Estimation of reef fish length by divers and by stereo-video: a first comparison of the accuracy and precision in the field on living fish under operational conditions. Fish Res 57:255-265

> Harvey E, Fletcher D, Shortis MR, Kendrick GA (2004) A comparison of underwater visual distance estimates made by SCUBA divers and a stereo-video system: implications for underwater visual census of reef fish abundance. Mar Freshw Res 55:573-580

Jennings S, Polunin NVC (1997) Impacts of predator deple- 
tion by fishing on the biomass and diversity of non-target reef fish communities. Coral Reefs 16:71-82

Kackar RN, Harville DA (1984) Approximations for standard errors of estimators of fixed and random effects in mixed linear models. J Am Stat Assoc 79:853-862

Kenward MG, Roger JH (1997) Small sample inference for fixed effects from restricted maximum likelihood. Biometrics 53:983-997

Kulbicki M, Sarramégna S, Letourneur Y, Wantiez L and others (2007) Opening of an MPA to fishing: Natural variations in the structure of a coral reef fish assemblage obscure changes due to fishing. J Exp Mar Biol Ecol 353: 145-163

Molloy PP, Reynolds JD, Gage MJG, Mosqueira I, Côté IM (2008) Links between sex change and fish densities in marine protected areas. Biol Conserv 141:187-197

Murrell P (2006) R Graphics. Chapman and Hall, London

> Nardi K, Jones GP, Moran MJ, Cheng YW (2004) Contrasting effects of marine protected areas on the density of two exploited reef fishes at the sub-tropical Houtman Abrolhos Islands, Western Australia. Environ Conserv 31: 160-168

Nardi K, Newman SJ, Moran MJ, Jones GP (2006) Vital demographic statistics and management of the baldchin groper (Choerodon rubescens) from the Houtman Abrolhos Islands. Mar Freshw Res 57:485-496

Olsen EM, Helno M, Lilly GR, Morgan MJ, Brattey J, Ernande B, Dieckmann U (2004) Maturation trends indicative of rapid evolution preceded the collapse of northern cod. Nature 428:932-935

Paul LJ (1976) A study on age, growth and population structure of the snapper, Chrysophrys auratus, in Hauraki Gulf, New Zealand. Fish Res Bull 13. New Zealand Ministry of Agriculture and Fisheries, Wellington

Pauly D, Christensen V, Guénette S, Pitcher TJ and others (2002) Towards sustainability in world fisheries. Nature 418:689-695

Pinheiro JC, Bates DM (2004) Mixed-effects models in S and S-plus. Springer, New York

Priede IG, Bagley PM, Smith A, Creasey S, Merrett NR (1994) Scavenging deep demersal fishes of the Porcupine Seabight, North-east Atlantic: observations by baited camera,

Editorial responsibility: Lisandro Benedetti-Cecchi, Pisa, Italy trap and trawl. J Mar Biol Assoc UK 74:481-498

R Development Core Team (2008). R: A language and environment for statistical computing. R Foundation for Statistical Computing, Vienna. www.R-project.org

Sattar SA, Jorgensen C, Fikson O (2008) Fisheries-induced evolution of energy and sex allocation. Bull Mar Sci 83: 235-250

Satterthwaite FF (1941) Synthesis of variance. Psychometrika 6:309-316

SeaGIS (2008) PhotoMeasure. SeaGIS Pty, Bacchus Marsh. www.seagis.com.au

St John J (1999) Ontogenetic changes in the diet of the coral reef grouper Plectropomus leopardus (Serranidae): patterns in taxa, size and habitat of prey. Mar Ecol Prog Ser 180:233-246

Sumner N (2008) An assessment of the finfish catch by recreational fishers, tour operators, commercial lobster fishers and commercial wetline fishers from the Houtman Abrolhos Islands during 2006. Fish Res Rep No. 175. Western Australia Department of Fisheries, Perth. www.fish.wa. gov.au/docs/frr/frr175/frr175.pdf (accessed 15 Oct 2008)

> Tetreault I, Ambrose RF (2007) Temperate marine reserves enhance targeted but not untargeted fishes in multiple notake MPAs. Ecol Appl 17:2251-2267

> van Herwerden L, Choat JH, Dudgeon CL, Carlos G, Newman SJ, Frisch A, van Oppen M (2006) Contrasting patterns of genetic structure in two species of the coral trout Plectropomus (Serranidae) from east and west Australia: introgressive hybridization or ancestral polymorphisms. Mol Phylogenet Evol 41:420-435

Watson DL, Harvey ES, Anderson MJ, Kendrick GA (2005) A comparison of temperate reef fish assemblages recorded by three underwater stereo-video techniques. Mar Biol 148:415-425

Watson DL, Harvey ES, Kendrick GA, Nardi K, Anderson MJ (2007) Protection from fishing alters the species composition of fish assemblages in a temperate-tropical transition zone. Mar Biol 152:1197-1206

> Willis TJ, Millar RB, Babcock RC (2000) Detection of spatial variability in relative density of fishes: comparison of visual census, angling, and baited underwater video. Mar Ecol Prog Ser 198:249-260

Submitted: November 7, 2008; Accepted: March 12, 2009 Proofs received from author(s): May 16, 2009 